\title{
Estimation of the Redox Potential of Lake Mariut Drainage System (Qalaa and Umum Drains)
}

\author{
Mohamed A. Hassaan ${ }^{1,}$, Osman A. El-Rayis ${ }^{2}$, Engy I. Hemada ${ }^{2}$ \\ ${ }^{1}$ Marine Pollution Lab, Marine Environment Division, National Institute of Oceanography and Fisheries, Alexandria, Egypt \\ ${ }^{2}$ Oceanography Department, Faculty of Science, University of Alexandria, Alexandria, Egypt
}

Email address:

mhss95@mail.com (M. A. Hassaan)

${ }^{*}$ Corresponding author

\section{To cite this article:}

Mohamed A. Hassaan, Osman A. El-Rayis, Engy I. Hemada. Estimation of the Redox Potential of Lake Mariut Drainage System (Qalaa and Umum Drains). Hydrology. Vol. 5, No. 6, 2017, pp. 82-85. doi: 10.11648/j.hyd.20170506.11

Received: October 10, 2017; Accepted: October 24, 2017; Published: December 11, 2017

\begin{abstract}
Qalaa and Umum Drains are agricultural drains and they are the main water sources for Lake Mariut Main Basin (LMMB). The water of Qalaa Drains is anoxic all the time because it contains considerable quantity of oxygen-consuming matter due to the discharge of the wastewater of Alexandria East Wastewater Treatment Plant (EWTP). The present work is aiming to measuring the dissolved and particulate forms of the two major elements $\mathrm{Mn}$ and Fe, besides making an estimation of the redox potential of Qalaa and Umum Drains using Mn and Fe that can differentiate between the oxic water of Umum Drain and the anoxic water of Qalaa Drain. The oxidation of Qalaa Drain water is one of the solutions to remove the main Qalaa Drain problem which is $\mathrm{H}_{2} \mathrm{~S}$.
\end{abstract}

Keywords: Heavy Metals, Drainage Systems, Umum Drain, Qalaa Drain, Lake Mariut, Egypt

\section{Introduction}

The Lake Mariut Main Basin (LMMB) is the principle basin for fishing, sometimes is called Proper Lake Mariut. The surface water of Lake Mariut is artificially not allowed to rise more than $-2.65 \mathrm{~m}$ below sea surface level. This is for the purpose to making it as a sink receiving agricultural and industrial sewage waste effluents from the surrounding lands. The agricultural drainage waters reach the lake from the catchments agricultural lands of Alexandria and Bohaira Provinces via two drains called Qalaa and Umum Drains, respectively. These drains particularly the first one also brings the wastewater of the villages and small cities bordering them along their courses, mostly untreated or sometimes primary treated. Qalaa Drain receives the wastewater resulted from an East wastewater treatment plant (EWTP) of primary treated sewage and industrial wastewaters of Alexandria City at rate reaching 915,790 $\mathrm{m}^{3} / \mathrm{d}$. The polluted Qalaa Drain discharges its effluent into LMMB at its southeast side. On the other hand Umum Drain is bordering LMMB at its far west side and a considerable portion of its water feeds LMMB through several breaches made illegally (by fishermen) at its east bank particularly in the part neighboring the southwest side of LMMB. [1-8].

Manganese is one of the most abundant metals in soils, where it occurs as oxides and hydroxides, and it cycles through its various oxidation states. Manganese occurs principally as pyrolusite $\left(\mathrm{MnO}_{2}\right)$, and to a lesser extent as rhodochrosite $\left(\mathrm{MnCO}_{3}\right)$. More than 25 million tonnes are mined every year, representing 5 million tons of the metal, and reserves are estimated to exceed 3 billion tonnes of the metal. Manganese is an essential element for all species. Some organisms, such as diatoms, mollusks and sponges, accumulate manganese. Fish can have up to $5 \mathrm{ppm}$ and mammals up to $3 \mathrm{ppm}$ in their tissue, although normally they have around 1 ppm [9].

Manganese compounds exist naturally in the environment as solids in the soils and small particles in the water. Manganese particles in air are present in dust particles. These usually settle to earth within a few days. Highly toxic concentrations of manganese in soils can cause swelling of cell walls, withering of leafs and brown spots on leaves. Deficiencies can also cause these effects. Between toxic concentrations and concentrations that cause deficiencies a small area of concentrations for optimal plant growth can be 
detected [9].

On the other hand, Iron is believed to be the tenth most abundant element in the universe. Iron is also the most abundant (by mass, 34.6\%) element making up the Earth; the concentration of iron in the various layers of the Earth ranges from high at the inner core to about 5\% in the outer crust. Most of this iron is found in various iron oxides, such as the minerals hematite, magnetite, and taconite. The earth's core is believed to consist largely of a metallic iron-nickel alloy. Iron is essential to almost living things, from micro-organisms to humans. A man needs an average daily intake of $7 \mathrm{mg}$ of iron and a woman $11 \mathrm{mg}$; a normal diet will generally provide all that is needed. It is strongly advised not to let the chemical enter into the environment because it persists in the environment [9].

The aim of this study is aiming to make a baseline for the concentration of dissolved and Particulate $\mathrm{Mn}$ and $\mathrm{Fe}$ in both Qalaa and Umum drains to make a calculation of the redox potential of Qalaa and Umum Drains using these two major elements Mn and Fe.

\section{Materials and Methods}

From all the selected stations, surface waters only were collected. 7 surface stations in Umum Drain and 8 surface stations covering the main course of Qalaa Drain Figure 1. The water samples were obtained using a 5-liter polyethylene sampling bottle, at least, 4 liters of each water sample was used for metals analysis. These were kept in a pre-acid washed and rinsed well with de-ionized water (DIW) polyethylene Jerry-cans. Trace metals can be concentrated by adsorption to Chelex chelating resin. [9, 10].

As soon as the water samples returned to the lab, the $4 \mathrm{~L}$ water was filtered through 0.45 um pore size membrane filters. These filters had been previously washed with dilute nitric acid and washed with de-ionized water (DIW) and dried to constant weight at the lab temperature $\left(\sim 25^{\circ} \mathrm{C}\right)$. Before collecting of the used filters, the retained material on the filter was rinsed with a few $(10 \mathrm{ml})$ of DIW, to remove salts and left to dry at the ambient lab temperature to constant weight (for a week) in a clean cabinet. The filtrate was immediately passed through a glass column containing Chelex-100 ion exchange resin in the ammonium form, to concentrate the heavy metals, according to [10]. After elution of the filtered water sample and washing with DIW, the retained metals on the Chlex-100 resin were eluted with acid and washing with DIW. Both were collected in a PTFE beaker (100 ml capacity).

Then the beaker was heated on a ceramic hot plate at $95^{\circ} \mathrm{C}$ in a special clean hood and allows the volume of the acid extract to evaporate to near dryness. One $\mathrm{ml}$ of $6-\mathrm{N}^{\mathrm{HNO}} 3$ was added to redissolve the residue and then collected in a 25 $\mathrm{ml}$ measuring flask using DIW before storing in a preacid cleaned $50 \mathrm{ml}$ polythene vial.

Moreover, the particulate heavy metals in the retained particulate matter were determined using the method described by [10]. The particulate metals retained on the membrane filters were digested in a Teflon beaker with about (50 $\mathrm{ml}$ of $2 \mathrm{~N}$ quartz - distilled nitric acid) for about four hours at $50^{\circ} \mathrm{C}$ to destroy any organic matter and to extract the particulate inorganic metals. The remained solution was completed to $100 \mathrm{ml}$ with DIW, the residue and its washing was centrifuged at 10,000 RPM and the supernatant solution was collected in the same Teflon beaker. Then the solution was evaporated to near dryness on the hot plate at $95^{\circ} \mathrm{C}$, redissolved in $1 \mathrm{ml}$ of $6 \mathrm{~N} \mathrm{HNO}_{3}$, then heated again, $10 \mathrm{ml}$ of DIW was added to dissolve the residue, left to cool and finally completed to the mark in a $25 \mathrm{ml}$ measuring flask with DIW. After mixing to attain homogenous solution it kept in clean plastic vials. The metals content in the acid extract solution was measured by a flame-Atomic Absorption Spectrophotometry [(AAS) Model Perkins-Elemer 2380], using the standard conditions recommended by the manufacturer of the AAS. The results were expressed in both (ug/L) and ug/g TSM.

In this study the regional average concentrations of $\mathrm{Mn}$ and $\mathrm{Fe}$ were studied from spring 2007 to winter 2008 for and the average concentration of both metals were used to estimate the redox potential of Qalaa and Umum Drains.

\section{Results and Discussion}

\section{1. $M n$}

In this study the major element that can differentiate between the oxic and anoxic waters is manganese. For Umum Drain, the regional average of D-Mn concentrations was $2.75 \mathrm{ug} / \mathrm{L}$. In the anoxic Qalaa Drain, during the whole study period its water contained the highest concentrations of $\mathrm{D}-\mathrm{Mn}$. The regional average of $\mathrm{D}-\mathrm{Mn}$ concentrations was $44.2 \mathrm{ug} / \mathrm{L}$.

In the oxic waters of Umum Drain, the surface waters, generally have P-Mn concentrations notably higher than the $\mathrm{D}-\mathrm{Mn}$. The regional average concentration of P-Mn was $49.25 \mathrm{ug} / \mathrm{L}$. In the anoxic water of Qalaa Drain, the regional average concentrations of $\mathrm{P}-\mathrm{Mn}$ was $7 \mathrm{ug} / \mathrm{L}$, which is almost one fifth of that, recorded in the oxic waters of Umum Drain.

Examining the content of TSM with Mn (ug Mn/g TSM), one can see that the TSM of the oxic water of Umum Drain was enriched with Mn (more than, at least, three times) than in the TSM of the anoxic waters of Qalaa Drain. This reflects dissolution of considerable amount of P-Mn led to the pronounced deficient in its Mn-content.

While by Examining total-Mn in Umum Drain (oxic) and Qalaa Drain (anoxic) waters, both have more or less same concentrations level. But difference has happened under the environmental factors $\left(\mathrm{H}_{2} \mathrm{~S}\right)$ reducing condition and dissolution of $\mathrm{Mn}$ as $\mathrm{Mn}^{+2}$ [11].

In Umum Drain, the value of D-Mn to T-Mn is the lowest value among the studied dissolved metals and this indicate that the $\mathrm{Mn}$ is present mainly in the form of insoluble Manganic $\left(\mathrm{Mn}^{+4}\right)$. While on the other hand in Qalaa Drain the values of D-Mn to T-Mn is considered that highest value among the studied metals and represents about $83 \%$, there for 
the soluble $\mathrm{Mn}^{+2}$ was considered to represent the overall reduced form of $\mathrm{Mn}$ under anoxic conditions. In the current study the suggested Mn solubility in Qalaa Drain is due to the anoxic condition of this Drain which reduced the $\mathrm{Mn}^{+4}$ or $\mathrm{Mn}^{+3}$ to more soluble $\mathrm{Mn}^{+2}$. El-Rayis et al., (1984) [11], pointed out that, water-bearing $\mathrm{H}_{2} \mathrm{~S}$ is able to solubilize $\mathrm{P}-\mathrm{Mn}$ of high oxidant states $\mathrm{Mn}^{+4}$ and/or $\mathrm{Mn}^{+3}$ by reducing them to the reduced and more soluble form of $\mathrm{Mn}^{+2}$. This could be the reason for the noticeable the high concentration of D-Mn.

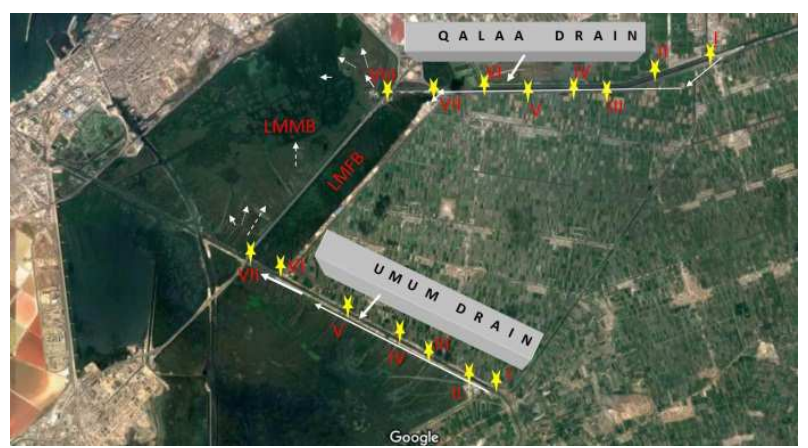

Figure 1. The sampling stations in the Two studied drains, (Qalaa and Umum Drains).

The values of the redox potential (Eh) in each of the two studied drains were done using Nernst Equation. The redox potential conditions of Qalaa Drain may support this convert of insoluble to soluble forms of Mn.

$$
\mathrm{E}=\mathrm{E}^{0}+\frac{0.059}{n} \times \log \frac{\left(\mathrm{Mn}^{+3}\right)}{\left(\mathrm{Mn}^{+2}\right)}
$$

Where: $-\mathrm{Mn}^{+3}$ is the Average of Particulate Mn.

$\mathrm{Mn}^{+2}$ is the Average of Dissolved Mn.

$\mathrm{E}=$ redox potential

$\mathrm{E}^{0}=$ the standard potential for acidic solution $=1.51$

$$
\mathrm{Mn}^{++} \frac{0.059}{n}=\text { equilibrium constant }
$$

$\mathrm{n}=$ number of electrons is shift from one atom to another at $25^{\circ} \mathrm{C}$ the combination of constants before the logarithm is $0.059 / \mathrm{n}$.

in Umum Drain:

$$
\mathrm{E}=1.51+\frac{0.059}{1} \times \log \frac{(49.25)}{(2.75)}=1.58 \text { volt }
$$

Where in Qalaa Drain,

$$
E=1.51+\frac{0.059}{1} \times \log \frac{(7)}{(44.2)}=1.46 \text { volt }
$$

The redox potential in the case of anoxic water may lead to the formation of almost all $\mathrm{Mn}$ in the soluble form (about $83 \%$ of the total $\mathrm{Mn}$ ).

$$
\left.\left.\mathrm{Fe}^{+3}\right) \mathrm{Fe}^{+2}\right) \frac{\mathrm{OH}^{-}}{\text {Soluble }} \mathrm{Fe}(\mathrm{OH})^{+2} \frac{\mathrm{OH}^{-}}{\text {inSoluble }} \mathrm{Fe}(\mathrm{OH})^{+3}
$$

The oxidation reduction cycle of iron $\left(\mathrm{Fe}^{+2} / \mathrm{Fe}^{+3}\right)$ is very important in controlling its concentration level in the surface

\section{2. $\mathrm{Fe}$}

For Umum Drain, in the surface water samples, the D-Fe regional average concentrations were $5.05 \mathrm{ug} / \mathrm{L}$. In the anoxic Qalaa Drain, the D-Fe regional average concentrations were $7.73 \mathrm{ug} / \mathrm{L}$, which is relatively high with respect to those for Umum Drain waters.

In Umum Drain, in the surface waters, the P-Fe regional average concentrations were $69.83 \mathrm{ug} / \mathrm{L}$. In the anoxic Qalaa Drain, the P-Fe regional average concentrations were 48.95 $\mathrm{ug} / \mathrm{L}$, which is remarkably lower than that observed in the oxygenated waters of Umum Drain. By Examining the Percentages of D-Fe to T-Fe there is a common feature that $\mathrm{D}-\mathrm{Fe}$ is representing values generally less than $50 \%$ of totalFe.

The percentage of D-Fe to T-Fe may not show significance difference between each of the two studied water (oxic and anoxic condition), and the values of D-Fe to T-Fe are 11 and $18 \%$ respectively. And almost all of Iron in both studied Drain are present in the insoluble ferric form $\mathrm{Fe}^{+3}$. The oxidation potential of iron in each of the two studied drains are calculated, from the below equation same as for $\mathrm{Mn}$.

In Umum Drain:

$$
\mathrm{E}=\mathrm{E}^{0}+\frac{0.059}{n} \times \log \frac{\left(\mathrm{Fe}^{+3}\right)}{\left(\mathrm{Fe}^{+2}\right)}
$$

where:- $\mathrm{Fe}^{+3}$ is the Average of Particulate Fe.

$\mathrm{Fe}^{+2}$ is the Average of Dissolved Fe.

$$
\mathrm{E}^{0}=0.77
$$

$$
\mathrm{Fe}^{++} \longrightarrow \mathrm{Fe}^{+++}+\mathrm{e}^{-}
$$

in Umum Drain

$$
\mathrm{E}=0.77+\frac{0.059}{1} \times \log \frac{(69.83)}{(5.05)}=0.837 \text { volt }
$$

Where in Qalaa Drain,

$$
\mathrm{E}=0.77+\frac{0.059}{1} \times \log \frac{(48.95)}{(7.73)}=0.818 \text { volt }
$$

The high different between the level of oxidation potential between $\mathrm{Mn}$ and Fe in Qalaa Drain indicate that the high reduction of $\mathrm{Mn}^{+3}$ to $\mathrm{Mn}^{+2}$ faster than $\mathrm{Fe}^{+3}$ to $\mathrm{Fe}^{+2}$ and this lead to high amount of dissolved $\mathrm{Mn}$ under anoxic conditions. The solubility of Fe and $\mathrm{Mn}$ in solution proceed through redox processes, which is controlled by the duration of the anoxic conditions (occurrence of ferric $\mathrm{Fe}^{+3}$ and Ferrous $\mathrm{Fe}^{+2}$ ) and simultaneously mediated by $\mathrm{pH}$, whose change from acidic to alkaline reaction include the following reaction of $\mathrm{Fe}$ with hydroxide ions:

water (as soluble ferrous form) which in turn affects its dominancy in water. This indication should occur due to the 
chelating of iron with soluble organic compounds present at less oxygenated waters leading to iron dominancy in water and/ or the reduction of ferric $\mathrm{Fe}^{+3}$ (insoluble) to Ferrous $\mathrm{Fe}^{+2}$ (soluble) because of low concentration of DO at watersediment interface (often zero) causing migration of soluble iron upward in the water column. Perhaps this is responsible for the slight increase of the level of D-Fe in Qalaa Drain than in Umum Drain [13].

According to the [12], the level of dissolved metals in the two studied areas are still far than those limits except for D$\mathrm{Mn}(44.2 \mathrm{ug} / \mathrm{L})$ in Qalaa which is become near from USEPA lower limit (50 ug/L). According to Distribution coefficient $\log \mathrm{Kd}$ results, Mn represents the lowest value in Qalaa Drain and this also one evidence that almost of $\mathrm{Mn}$ in the anoxic water of this drain is present in the dissolved form [14-17].

\section{Conclusion}

This study indicated that the solubility of $\mathrm{Fe}$ and $\mathrm{Mn}$ in both drains proceed through redox processes, which is organized by the period of the anoxic conditions. The D-Mn could be converted to P-Mn by the oxidation of D-Mn and this will lead to precipitate D-Mn into P-Mn. The oxidation of the water of Qalaa Drain is one of the solution to remove the the main Qalaa Drain problem which is $\mathrm{H}_{2} \mathrm{~S}$. The oxidation of Qalaa Drain waters, could be by pump the water from Umum Drain to Qalaa Drain though Lake Mariut Fishery Basin (LMFB), or by constructing a canal to convert the way of Qalaa Drain and the dilution of the water could happen through this canal by taking water from ElMahmoudia canal if it possible.

\section{References}

[1] EI-Rayis, O. A. and Hinckely, D. (1998). Existing environmental conditions in Lake Maryout south of Alexandria, Egypt: 2- Hydrologic. The 8th conference On Environmental Protection is a Must. NIOF. VEA, ISA and SFD, Alexandria, Egypt, 5 - 7 May 1998, pp. 13 (Abstract).

[2] Samaan, A. A. and Abdel-Moneim, M. A. (1986). Some physical features of the polluted basin and fish farm in Lake Maryout, Egypt. Bull. Inst. Oceanogr. \& Fish. ARE 12: 149163.

[3] EI-Rayis, O. A. and El-Sabrouti, M. A. (1997). Lake Maryout: pollution problems and proposals for restoration. Fresenius Environ. Bull. 6: 598 -604.

[4] Metcalf and Eddy International, (1997b). Enviromental Assessment. June 30, 1997. AWP Phase II, usaid Proj, 2630100. prepared by Metcalf and Eddy, Alexandria, Egypt.
[5] Nagy, H. and Salem, A. (2003). Evaluation of drainage water quality of reuse- A case study of Umum Drain in Egypt, Lowland Technology International Vol 5, No 2, 27-38, December 2003, ISSN 1344-9656.

[6] Metcalf and Eddy International, (1997a). Technical report: chemical and biological characterization of Lake Mariut. Draft, Feb. 1997. AWP Phase II, usaid Proj, 263-0100. prepared by Metcalf and Eddy, Alexandria, Egypt.

[7] Youssef, D. H. (1999). Behavior of some heavy metals in sulphidic aquatic conditions. Ph. D. Thesis, Faculty of Science, Alexandria University, pp. 145.

[8] ALAMIM - SMAPIII. (2007). Alexandria Lake Mariout Integrated Management, Stocktaking analysis (a), background material, 3rd draft, Alexandria 2007. pp 49.

[9] Hassaan, M. A. (2010). Study on concentration of some heavy metal in the lower reach of Qalaa and Umum Drains to control metla pollution in Lake Mariut, M. Sc. A Thesis, Faculty of Science, Alexandria University. $236 p$.

[10] Abdullah M. I. and Royle L. G (1974). A study of the dissolved and particulate trace elements in the Bristol Channel. J. Mar. Biol. Ass. U. K., 54-581-597.

[11] EI-Rayis, O. A.; El-Sayed, M. M. and Turki, A. J. (1984). A preliminary / investigation for level and distribution of some heavy metals in coastal water of Jeddah, Red Sea, during 1981 - 82. In: Symposium on "Coral Reef Environment of the Red Sea"; Jeddah, Saudi Arabia. Jan. 14-18. pp. 147-169.

[12] USEPA, (2009). http:// www.epa.gov/safewater/standards.html

[13] El-Rayis, O. A. and Saad, M. A. H. (1990). Heavy metal pollution in lagoon. Mary out, on the southern coast of the eastern Mediterranean Sea. J. KAU. Mar. Sci, vol. 1: 17-26.

[14] El-Rayis O. A., Hassaan M. A. and Hemada E. I., Suitability of Lake Mariut Drainage System (Qalaa and Umum Drains Waters) for Water Reuse, (2014): Blue Biotechnology Journal, 3(2) p 265-277.

[15] El-Rayis, O. and Hassaan, M. (Are the Two Natural Drains Filling Lake Mariut with Water Polluted with Heavy Metals? Solution/s of its Pollution Problem. 2nd conference of science colleges students, Faculty of Science, Alexandria university, Alexandria, Egypt 2011.

[16] Hassaan, M. A., and Ali, H. R. (2017). Fresh Water Pollution and Heavy Metals Removal. 1st Edition, Publisher: Lambert Academic publishing, e-book [ISBN: 978-3-659-57770-3]. pp. 220.

[17] Hassaan, M. A., El Nemr, A., and Madkour, F. F. (2016).Environmental Assessment of Heavy Metal Pollution and Human Health Risk, American Journal of Water Science and Engineering. 2(3) pp. 14-19. 